\title{
Reconciliation through Description: Using Metadata to Realize the Vision of the National Research Centre for Truth and Reconciliation
}

BRETT LOUGHEED

Archives and Records Centre, University of Winnipeg, Winnipeg, Canada

RY MORAN

National Research Centre for Truth and Reconciliation, University of Manitoba, Winnipeg, Canada

\section{CAMILLE CALLISON}

University of Manitoba Libraries, Winnipeg, Canada

\begin{abstract}
This article will discuss the bistory and context surrounding the document collection and statement gathering mandates of the Truth and Reconciliation Commission of Canada and the challenges the newly established National Research Centre for Truth and Reconciliation will face in applying the Commission's metadata set in the realization of its vision. By working respectfully with Indigenous people through the implementation of Indigenous knowledge best practices and the application of contrasting traditional/nontraditional, archival/user-generated, and institutional/Indigenous descriptive elements, the Centre will attempt to create a "living archive" and facilitate Indigenous participation, collaboration, and ultimately, the process of reconciliation.
\end{abstract}

KEYWORDS Indigenous knowledge, trusted repository, subject and classification bias, digital archives, Indigenous archives, truth and reconciliation, Residential Schools

(C) Brett Lougheed, Ry Moran, and Camille Callison

Received August 2014; revised December 2014; accepted January 2015.

Address correspondence to Brett Lougheed, Archives and Records Centre, University of Winnipeg Library, 515 Portage Avenue, Winnipeg, MB R3B 2E9, Canada. E-mail: b.lougheed@ uwinnipeg.ca 
For over one hundred and fifty years, Canada's landscape was dotted with Residential Schools. Indigenous children were forcibly removed from their homes to attend these schools, which were administered by the Canadian government and various church entities in the goal of assimilating Indigenous language, identity, and traditional culture, customs, and values. Some of these schools provided children with education, while others provided exposure to fatal diseases, such as tuberculosis, or traumatic emotional, physical, and even sexual abuse. Others provided makeshift accommodations comprised of tents, cots, and a lack of running water. All constituted a direct and concerted attack on Indigenous cultures, identities, and families.

These schools and residential institutions represent one of the darkest and most shameful undertakings in Canadian history. The societal effects of Residential Schools continue to play out on a daily basis within and amongst Métis, Inuit, and First Nations communities across the country. Over the course of the past five years, the Truth and Reconciliation Commission of Canada (TRC) has toured from coast to coast to coast in an effort to collect the oral and documentary history of these schools. Key within this process is providing Residential School Survivors the opportunity to be heard-for their voice to be respected-and for the challenges they faced before, during, and after attending a school to be acknowledged.

Over the course of its mandate, the TRC successfully acquired and described millions of digital records from across Canada from a variety of sources including government agencies and church-run archives. To do so, the TRC relied on contractors hired by the TRC and the production of records from entities themselves. This varied collection methodology-one driven primarily by budget-means that the data set collected by the TRC was derived from multiple sources, often with multiple configurations of metadata or description. In being the agency responsible for the preservation and access to these materials, the National Research Centre for Truth and Reconciliation (NRCTR) will face challenges in optimizing the metadata used to describe the TRC's records in realizing its vision as expressed by the University of Manitoba and its partners in their bid document. By utilizing technological advances and incorporating Indigenous perspectives on description, the NRCTR will attempt to overcome these challenges to normalize and augment the existing descriptions to create a "living archive" that facilitates Indigenous participation, collaboration, and ultimately, the process of reconciliation.

\section{THE TRUTH AND RECONCILIATION COMMISSION OF CANADA}

The TRC derives its mandate from Schedule $\mathrm{N}$ of the Indian Residential Schools Settlement Agreement (IRSSA). The Settlement Agreement generally ended the numerous individual litigations that were working their way 
67 through the courts in addition to the widely criticized Alternative Dispute

68 Resolution process implemented by the Canadian government. ${ }^{1}$ In addition

69 to creating the Truth and Reconciliation Commission, the Settlement Agree-

70 ment also created the Common Experience Payment process (CEP) and the

71 Independent Assessment Process (IAP), the combination of which were the

72 compensatory elements of the Settlement Agreement.

73 Following a failed attempt at implementing the TRC in 2008, Justice

74 Murray Sinclair (Chair), Chief Wilton Littlechild, and Marie Wilson were

75 appointed as Commissioners in July 2009 to lead the work of the TRC.

76 By January of 2010, the first Directors of the Commission were hired and

77 work commenced in earnest to implement the TRC's mandate. Core to this

78 early period of the Commission's existence was a significant amount of

79 reflection and dialogue over the various elements of Schedule N. With-

80 out a doubt, the TRC's mandate was broad, encompassing elements as

81 diverse as national events, community events, document collection, state-

82 ment gathering, commemoration projects, a final report, regional liaisons,

83 public education through mass communications, reconciliation, the creation

84 of a National Research Centre, a Survivors Circle, and a final closing event.

85 This scope and mandate was without precedent in Canadian history and

86 would present an enormous operational and financial challenge to the

87 Commission.

88 Of the many areas of the Commission's mandate, the statement gathering

89 and document collection mandate formed the core processes that generated

90 the majority of the records in the possession of the TRC. These same records

91 also form the core collection of the records to be transferred to the NRCTR.

\title{
STATEMENT GATHERING
}

The Statement Gathering mandate of the TRC appears in multiple locations throughout Schedule $\mathrm{N}$ with the core obligation reading as follows:

\begin{abstract}
The Commission shall coordinate the collection of individual statements by written, electronic or other appropriate means. Notwithstanding the five year mandate, anyone affected by the IRS legacy will be permitted to file a personal statement in the research centre with no time limitation. The Commission shall provide a safe, supportive and sensitive environment for individual statement-taking/truth sharing. The Commission shall not use or permit access to an individual's statement made in any Commission processes, except with the express consent of the individual. ${ }^{2}$
\end{abstract}

Using this paragraph as guidance on the general intent behind the Statement Gathering process, the Commission began to operationalize the process. Core beliefs that were central in the statement gathering process were that: 
a. Statement providers were free to share whatever elements of their experience they wished with the Commission in as much or as little detail as they chose.

b. The statement gatherer's primary role was that of a listener and facilitator, and that the process should not be interrogatory.

c. The statement provider was in charge of the process and could stop or start their statement at any point in time.

d. The well-being of the statement provider was paramount throughout the process and the goal was to provide as safe and supportive an atmosphere and experience as was possible throughout the process.

e. Anyone, including former staff, Day School Survivors, victims of the "Sixties Scoop," 3 and Intergenerational Survivors could provide a statement to the TRC.

The Commission also felt it was critical to provide those that wished to share a statement with the TRC as much choice and latitude in the process as possible. As a result, statement providers could offer both public and/or private statements, which could be given both individually or as part of a group in their language of choice. Those individuals who gave private statements were also provided with the additional choice between having their statement digitally recorded on audio or video, written down, or not recorded at all. Those individuals who gave statements in a public setting had the choice of participating in a Sharing Panel session in front of one of the Commissioners, or in a Sharing Circle moderated by an Elder, Survivor Committee member, or other respected person.

\section{DOCUMENT COLLECTION}

Just as the Commission was required to collect as much oral history of the Residential School system and legacy as possible, so too was it required to "[i]dentify sources and create as complete an historical record as possible of the IRS system and legacy." ${ }^{4}$ The records collected by the Commission were to be "preserved and made accessible to the public for future study and use." These short few lines would end up becoming one of the Commission's greatest challenges as it faced obstacles including cost, relevance, reluctance, complexity, logistics, and outright resistance. This is all despite what many, including more than one judge, considered to be fairly clear language on the legal obligations of signatories to produce records to the TRC. ${ }^{6}$

Despite the challenges facing the Commission, a number of core principles underscored the TRC's approach to collecting the records. These were:

a. That the collection should be as full and complete as possible, and that any limitation of collection to documents where "residential schools" simply 
appeared in the title or naming of the file would fall far short of a full and complete history.

b. That a wide variety of government departments were involved in the residential school system including the Department of Defence, Health Canada, Aboriginal Affairs, Agriculture, the RCMP, the Department of Justice, and Privy Council Office to name a small selection.

c. That all media types were in scope, which includes, but is not limited to, video, film, audio, photographs, glass plate negatives, maps, and e-mail.

d. That all record types were in scope including, but not limited to, personnel files, correspondence, memos, official reports, minutes, and health records.

e. There were very few reasons for excluding records from production. The acceptable reasons were very narrow and focused primarily on solicitor-client privilege and some provisions pertaining specifically to police investigation files (i.e., method, confidential informants, young offenders, etc.).

f. That the provenance and file structures related to a record should be captured as accurately as possible with the goal being for future researchers to understand not only the content of the record but also where it originated and the context from which it came.

To accomplish these goals, in 2011, the TRC awarded a contract to a consortium of firms to provide services in the areas of project management, database hosting and software provision, historical research/records review, screening and metadata tagging, and digitization. The initial ambition of the TRC was for this team to conduct the vast majority of the document collection from the church entities while the federal government undertook production responsibilities from its own departments and from Library and Archives Canada (LAC). However, these ambitions were soon presented with challenges.

Upon starting the document collection process in a number of the church archives, the TRC quickly realized that the volume of records to be identified and scanned surpassed expectations, resulting in unsustainable costs given the TRC's limited budget. At the same time, the Government of Canada was also experiencing its own challenges funding and initiating the flow of documents from its own archives. By 2012, the document collection processes, with the exception of government collection of active and semi-active records from government departments, had largely ground to a halt while all parties assessed what their legal obligations were under the Settlement Agreement. For the federal government, the difficulties of producing the records from LAC resulted in a court challenge by the TRC, while for the churches, requests made by the TRC resulted in some entities taking on the challenge of identifying, scanning, and producing the records of their archives while others stalled production. By late 2012, all parties were 
189

190

191

192

193

194

195

196

197

198

199

200

201

202

203

204

205

206

207

208

209

210

211

212

213

214

215

216

217

218

219

220

beginning to realize that the success of the document collection effort and the corresponding satisfaction of binding legal obligations were in great jeopardy. Thankfully, despite a number of ongoing challenges, many rose to the occasion and, by mid-2013, documents were again flowing from both church and government archives into the TRC's database.

\section{THE TRUTH AND RECONCILIATION COMMISSION DATABASE METADATA SCHEMAS}

The digital records and accompanying metadata created and accumulated by the Truth and Reconciliation Commission of Canada are stored within seven separate databases that comprise the encompassing "TRC Database." The seven component databases are the IRS [Indian Residential Schools] School Authority Database; Audio/Video Statement Database; National Research and Analysis (NRA) Database; Church Archival Records Database; Red, Black, and School Series Database; Active and Semi-Active Government Records Database; and Library and Archives Canada Archival Records. Each of these databases is described in more detail below.

The IRS School Authority Database includes information about every Residential School documented in the records created or accumulated by the TRC. The authority records contained in the IRS School Authority Database attempt to track titular or geographical changes via the school name variation field and the opening and closing dates of those variations, as well as by listing all predecessor and successor institutions with a more detailed history attached as a Portable Document Format (PDF) file. These "school narratives," originally written to support the federal government's research, CEP claims, and IAP work, were supplied to the TRC by the government. The narratives were to form the government's basis of understanding of Residential Schools and include information on a variety of issues including known instances of abuse, identifying information (i.e., opening and closing dates), and references to the records created or obtained by the TRC in the creation of the narratives. Multiple versions of these narratives were submitted to the TRC due to the ever-evolving understanding of events at each of the schools. ${ }^{8}$

The content populating the Audio/Video Statement Database consists of the testimonies provided by IRS Survivors, their families (Inter-Generational Survivors), former staff, and other individuals with affiliations to Residential Schools about their school experiences and the long-lasting impacts on their daily lives and on the lives of those close to them. These statements were recorded and segments comprising the entire recording are made accessible to the database user. The metadata elements utilized to describe these statements are divided into three distinct categories: information pertaining 
to the statement (including whether the statement was public or private), information pertaining to the statement giver (including his or her affiliation with a particular school(s)), and notes about the statement provided by the statement gatherer. In addition, a full transcript of the recording, and the ability for the user to download the full transcript or the statement gatherer's field notes ${ }^{9}$ as PDFs, is available on the site.

The National Research and Analysis (NRA) Database consists of digitized records created by the Government of Canada pertaining to Indian Residential Schools accumulated by Aboriginal Affairs and Northern Development Canada (AANDC), as well as church records requested by AANDC, in its efforts to implement the Indian Residential Schools Settlement Agreement (IRSSA). This database is an amalgamation of several separate issue-specific databases created by AANDC as a response to litigation. PDFs of the records accompany the metadata in this database as well as a QR code that links to the record when scanned. In addition to the descriptive and administrative metadata employed in this database, the records also include what are called Tracking Codes, which indicate the presence of subjects of importance to the TRC in carrying out its mandate and in writing its reports (i.e., the mention of missing or deceased children). Unfortunately, due to the low resolution bi-tonal scanning protocols employed by the Government of Canada, these records have not, and likely cannot, undergo Optical Character Recognition (OCR) processing rendering full text search impossible.

The Church Archival Records Database consists of the digitized records contributed by various church entities throughout Canada to assist the TRC in realizing its mandate. PDFs of the digitized records are viewable within the database. The metadata elements utilized to describe the church archival records can again be sub-divided into three categories: Record Details, Container/Citation Information, and OCR Data. During the post-processing phase of digitization, the digitized church archival records undergo OCR processing and the output of that data is viewable within the OCR Data category of the document's metadata record. This allows for keyword searchability of this data, consequently improving the discoverability of desired records by TRC researchers.

Unfortunately, there is considerable variability in the metadata of the Church Archival Records Database. This variability can be attributed to the differences in descriptive practice amongst the close to one hundred individual church archives that were within scope for TRC document collection processes. For example, some church archives utilized traditional library classification systems such as Library of Congress, while others utilized archival descriptive standards such as the Rules for Archival Description. In addition, a funding shortfall and the inability for the TRC to cover all costs associated with the proper identification, review, scanning, and upload of church documents to the TRC Database meant that unlike the rest of the records 
in the database, the earliest church records digitized by the TRC were not described at the item level although efforts are underway by the some of the churches to address this.

The documents stored and managed within the Red, Black, and School Series Database consist of three particular series of records within Library and Archives Canada's (LAC) holdings. The Red and Black Series are the results of the Department of Indian Affairs' attempt in 1923 to implement a central registry filing system for incoming and outgoing correspondence at the Department's headquarters. The Red Series consists of records pertaining to the Department's relations with Indigenous people in eastern Canada while the Black Series documents the Department's relations with Indigenous people in western Canada. Within these series of records, correspondence pertaining to Residential Schools was assigned a subject number to ease in these files' reference. ${ }^{10}$ The School Files Series is a grouping of records within the Indian and Inuit Affairs Program sous-fonds (part of the Department of Indian Affairs and Northern Development fonds) documenting all aspects of Indian Residential School administration in Canada including attendance and discharge records, inspection reports, and medical records among other types of records. ${ }^{11}$

Scans of the digitized microfilm housed in LAC are viewable within the database, labeled as "Assets." The metadata used to describe these records include information about the record (Record Details) and about the originating physical containers at LAC (Container Information). The majority of the records in this database are described at the file level, while some are described at the microfilm reel level. Like the first digitized church records, there are very few item-level descriptions available for this series of records. There is duplication of data within certain elements of these descriptions, specifically with reference to location or reference information. As with the NRA records, the Red, Black, and Schools Series of records have not undergone OCR processing. While the images were scanned at higher quality than those that are in the NRA database, the presence of many handwritten records will make OCR scanning of this collection challenging at best.

The Active and Semi-Active Government Records Database includes the records digitized by the Government of Canada pertaining to Indian Residential Schools and submitted to the Truth and Reconciliation Commission for its review and retention. These records are considered active or semi-active as the potential for use in executing business functions by the creating government agency is still a possibility. As such, some of these records document the Government of Canada's more recent interactions with Indigenous people with respect to Residential Schools. These records were not yet classified as archival and had not yet been transferred to Library and Archives Canada for permanent retention. Digitized PDFs of these records are viewable within the database. 
Finally, the LAC Archival Records database consists of digitized records within the holdings of Library and Archives Canada, with the exception of the Red, Black, and School Series records. The structure and layout of this database is identical to the Church Archival Records Database. Just as in the Church Archival Records Database, PDFs of the records are viewable within the database and the metadata for the LAC records are divided into the categories of Record Details, Container/Citation Information, and OCR Data for each item. The data in the LAC Archival Records database is more consistent in its fulsomeness and structure than the data populating the Church Archival Records Database, likely owing to the fact that there is little discrepancy in descriptive practice at LAC. Until September 2014, these records were identified, reviewed, and scanned by the TRC using the document collection team and processes utilized in the church projects. As of September 2014, the Government of Canada will be assuming control over these processes. The impact on metadata consistency is not yet known.

\section{THE TRUTH AND RECONCILIATION COMMISSION DATABASE SEARCH/BROWSE FUNCTIONALITY}

Approved users with valid security certificates who are granted access to the web interface of the TRC Database through the graphical user interface have limited options to browse the records and their metadata, although more advanced search options exist via the desktop client, which is primarily used for data input. Upon authentication to the system, the only access mechanism available to users is the ability to search across these seven separate databases, either by keyword or in an advanced search. Searches conducted scan a pre-selected number of fields in each database in an attempt to rationalize searches across the multiple datasets.

For the keyword search, users have the option of selecting whether they would like the search to include all of their chosen keywords, any of the keywords, or an exact phrase. The user is presented with search result sets listing the number of records containing the search term within their metadata for each individual database. The user selects the result set for a particular database and is presented with a listing of the relevant records, which includes a few descriptive metadata elements for each record. ${ }^{12}$ The user can then view a record and its associated metadata by clicking on the highlighted value in the search result set.

An Advanced Search option is presently available only for the records in the Church Archival Records Database and the Library and Archives Canada Archival Records database as these are the only two databases employing the same metadata schema. As a result, users can select limits on their searches across these two databases resulting in more refined search result sets. 
Advanced search allows users to limit their searches by a number of common metadata elements including the originating archival institution, school name, document ID or type, fonds or sous-fonds, language, issues, ${ }^{13}$ priority issues (namely the mention of cemeteries or deceased or missing children), and file name descriptor or title. Users can also limit their search by the name, position/location, ID, or birth or death dates of individuals listed in these metadata records. Finally, within the advanced search, users can limit their search by the actual or estimated cover or document date, or they can limit their search to a full text search of the OCR data in these records. The other five databases are excluded from the advanced search and can only be accessed via a keyword search.

\section{THE CREATION OF THE NATIONAL RESEARCH CENTRE FOR TRUTH AND RECONCILIATION}

By 2012, it was becoming clear that the million-plus records and three thousand statements collected by the TRC would require an appropriate long-term home. As per Schedule N, the Commission undertook a process to establish the National Research Centre, which included, among other things, a national conference, followed by a national and public call for proposals, lastly followed by an extensive review process by the TRC of the proposals received.

On June 21, 2013, the University of Manitoba, in conjunction with its partners, was officially named the host of the NRCTR. For the university, this was the culmination of many years of hard work, which included participation in the TRC's first National Event in Winnipeg, the hosting of a Statement Gathering program, a historic apology by the president, followed by an extensive consultation and bid-writing process.

\section{DESCRIPTIVE CHALLENGES FACING THE NATIONAL RESEARCH CENTRE FOR TRUTH AND RECONCILIATION}

By becoming the steward for the written and oral histories of the Indian Residential School experiences of Survivors, the NRCTR can play a central role in the preservation, reclamation, and intergenerational transfer of Indigenous knowledge and history. Marie Battiste states that "the task for Indigenous academics has been to affirm and activate the holistic paradigm of Indigenous knowledge to reveal the wealth and richness of Indigenous languages, worldviews, teaching and experiences, all of which have been systematically excluded from contemporary education institutions and from Eurocentric knowledge systems." 14 Today, barriers still exist within libraries 
and archives for Indigenous users. To combat these barriers, an understanding of Indigenous peoples' sense of history or worldview, importance and validity of a dynamic culture of oral traditions, and issues of decolonization and re-empowerment are important for archival professionals to understand when working with Indigenous communities and/or their archival materials. Indigenous people's valuing and understanding of Indigenous knowledge is often vastly different from the Eurocentric paradigm. In order for the NRCTR to challenge the Eurocentric paradigm that currently exists in the records of the TRC, Indigenous voices need to be acknowledged and respected. James (Sákéj) Youngblood Henderson writes, "One task of decolonization is to replace the sameness of universality with the concepts of diversity, complementarities, flexibility, and equity or fundamental fairness."15

The NRCTR has committed itself to incorporating Indigenous knowledge through the adoption of five best practices: ${ }^{16}$

\section{Protect and preserve Indigenous knowledge(s) in a variety of mediums} for use by current and future generations in a respectful and sensitive manner: The University of Manitoba is prepared to steward the Truth and Reconciliation Commission's archives and provide a secure environment to make them widely accessible digitally, subject to privacy law and culturally appropriate access protocols." 17

2. Provide a welcoming environment and assistance for First Nations, Métis, non-status and Inuit people to access this knowledge: Archives open-door policies and use of digital archival technology will facilitate access to the archival holdings, promote information sharing and research in an integrated approach with culturally relevant practice with Elders and other health supports. Facilitating ease of access and use becomes a very important part of the reclamation and intergenerational transfer of Indigenous knowledge and history. One way in which this can be accomplished is by incorporating Indigenous perspectives on description. First Nations, Métis, and Inuit people in Canada have been undertaking a process of decolonization. Consequently, many names, both of their tribal groups and geographic locations, have been changed to traditional names and spellings. As author Jenna Walsh notes, it is important to work with user communities, particularly Indigenous communities, in order to select the most appropriate languages for description. ${ }^{18}$

3. Seek direction from communities on proper protocols regarding access and care of their culturally sensitive information: Survivors and communities are incorporated not only into the governing framework of the Centre, but also need to be consulted on how the records should be cared for and made accessible. Dialoging with community is a highly important element of the NRCTR's development. It is essential the NRCTR listen to the needs of community, solicit input and guidance from community and build bridges with community members. The NRCTR will carefully 
consult with Survivors, Intergenerational Survivors, and communities from across Canada in a respectful process commencing in 2015. By working proactively and respectfully with Survivors and communities the NRCTR will attempt to help in overcoming barriers to Indigenous peoples.

4. Respect the First Nations, Métis and Inuit cultural concept of copyright with regard to Aboriginal history or heritage, which is often located in but not limited to oral traditions, songs, dance, storytelling, anecdotes, place names, hereditary names, and other forms of indigenous knowledges: Archives play a crucial role in collecting and preserving oral traditions, but there are many sensitive issues involved. Oral histories belong to Nations, bands, families, and individuals and as they were transferred to material manifestations, many copyright and intellectual property issues have developed. Archival and preservation programs that work with oral history collections must incorporate different levels of access for different user groups and members of the community. In an effort to facilitate education, research and information sharing while maintaining cultural continuity, the NRCTR has gathered together a team of experts and Indigenous Elders to address privacy, access, and copyright concerns and develop an Access Policy. Dialogue has already taken place and will continue until these protocols are in place to address privacy, access and copyright.

5. Provide opportunities and access to training and employment for First Nations, Métis, Inuit, and non-status people: The key to empowering Indigenous people is to educate, train, and equip Indigenous professionals to be the "keepers" and custodians of their own traditional knowledge in its varied forms. Consequently, a process of decolonization takes place and the control and custody of Indigenous knowledges and ways of knowing are reclaimed by Indigenous people.

Several projects are underway within library and archives communities in North America and around the world attempting to better incorporate Indigenous knowledge into traditional (i.e., Eurocentric) knowledge systems. The NRCTR may wish to incorporate similar changes into the metadata of the records in its holdings so that Indigenous users might efficiently create, locate, and access Indigenous knowledge within the database. Another way in which Indigenous users might become empowered as "keepers" of Indigenous knowledge is through the NRCTR's inclusion of participatory archiving, whereby the stories, comments, and content created by Indigenous communities could be given equal prominence to the content and descriptions provided by church and state, and made a part of the permanent archive of the NRCTR.

In the successful proposal to host the Centre submitted by the University of Manitoba and its partners, the authors state that the records created and accumulated by the TRC would form the center of "a unique participatory 
archive" that would utilize innovative digital technologies to "enable survivors, scholars and others to use the records to tell many stories: the story of each residential school survivor, of families, of communities, of schools, of regions and of the country." 19 This participatory archive would create a "network of virtual communities of former residential school students, their families and others from coast to coast" and allow users to "shape the archives by adding descriptions, arrangements and commentary to the records." 20 The records would also be made accessible to those individuals who rarely use computers or who use outdated hardware/software, people with limited literacy skills, and people for whom English is not a first language, including those who speak Indigenous languages, ${ }^{21}$ in an effort to engage as broad an audience as possible in the spirit of building trust and facilitating reconciliation. In its current state, the metadata utilized to describe the records of the Truth and Reconciliation Commission, as structured within the TRC Database, present several challenges to realizing the vision of the NRCTR.

The current TRC Database does not include any participatory archiving elements, particularly the ability for users to add descriptions, arrangements and commentary to the institutional descriptions provided to the TRC by the Government of Canada, LAC, and the various church entities. The TRC Database was specifically designed for the ingest of over four million records in three years and robust public access tools were not primary considerations or objectives of the TRC. However, over time, it is clear that the digital asset management system that will host the records of the TRC at the NRCTR will need to incorporate these features in order to allow users to shape the archive as expressed in the University of Manitoba and its partners' proposal. The Reciprocal Research Network and the Plateau Peoples' Web Portal are two excellent models for the NRCTR to follow in establishing a participatory archive that would build on the metadata provided to the TRC through the addition of user-generated content in documenting these records from various perspectives and through numerous contextual lenses.

The Reciprocal Research Network (RRN) is a joint project co-developed by the Musqueam Indian Band, the Stó:lō Nation/Tribal Council, the U'mista Cultural Society and the Museum of Anthropology. The RRN is "an online tool to facilitate reciprocal and collaborative research about cultural heritage from the Northwest Coast of British Columbia" by enabling "communities, cultural institutions and researchers to work together." 22 Participatory elements built into the RRN include the ability for authenticated users to create and collaborate on projects, upload user-generated content, and establish discussion forums and social networks. ${ }^{23}$ Mukurtu is open-source content management software that is designed specifically for preserving cultural knowledge and acting as a "catalyst for ongoing dialogue about sharing, making and reproducing cultural materials and knowledge." ${ }^{24}$ It is designed specifically for use by Indigenous communities. One such instance is employed by several tribes in Washington State in the creation of the Plateau Peoples' Web Portal. ${ }^{25}$ The 
Plateau Peoples' Web Portal allows for tribes, scholars, and originating institutions to upload content, create collections, add metadata/tags/comments, map content, and add audio/video/textual narratives to the existing content. ${ }^{26}$ Mukurtu project lead Kimberly Christen Withey notes that in this way, Mukurtu is "a powerful tool in reconstructing family and community histories disrupted by national policies of forced assimilation." 27

The NRCTR may wish to take cues from these projects when implementing participatory archive elements to its digital asset management system. Users of the system will want to be able to add comments, tags, or descriptions (possibly as text, audio, or video) to digital objects, as long as they are authenticated within the system and are not restricted from accessing the records. ${ }^{28}$ Users will likely also wish to create their own collections or aggregations of NRCTR content, and add their own content and metadata to these user-generated collections. It is also likely imperative that users have the ability to interact with one another via commentary, discussion forums, or other social networks to safely engage in moderated conversations about IRS experiences and reconciliation.

Survivors, Inter-Generational Survivors, Indigenous communities, researchers, the University of Manitoba and its partners, and other stakeholders would need to be engaged in conversation to determine how best to incorporate participatory archiving into the system so that it meets the requirements of its user communities. The NRCTR will want to ensure that the content and metadata generated by users are preserved and integrated into the official documentary record of the NRCTR in the creation of a "living archive," which would be continually updated and aggregated to reflect the dynamic nature of Indigenous knowledge. Camille Callison writes, "The dynamic quality of Indigenous knowledge is such that it is sustained, transformed and continues to remain dynamic producing 'new' knowledge in new mediums. ... Indigenous Knowledge is constantly evolving in response to a changing environment." ${ }^{29}$ Following the initial dialogues the NRCTR has had with Survivors and Indigenous communities, two dominant messages have been persistent-one, that the Residential School Survivor can never be forgotten in any presentation of the records, and two, that the Centre must be a place where culture and traditional practice lives. In so doing, the Centre must ensure that the records are brought to life and that they are appropriately interwoven with Indigenous cultures.

The NRCTR can also learn from the experience of the RRN in terms of metadata normalization and accessibility issues it faces in striving to realize its vision. For example, the metadata that accompanies the digital objects contributed by the RRN's institutional partners is exported from diverse collection management systems and imported into the RRN. Consequently, the system had to include the ability to normalize the contributed metadata to a common standard to allow for cross-collection search and browse functionality. The RRN displays the original metadata provided by the contributing 
institution and the normalized metadata in two separate tabs in order to indicate the normalization process and to demonstrate the authenticity of the record.

The NRCTR faces a similar metadata normalization challenge. The seven databases comprising the TRC Database utilize six different metadata schemas. ${ }^{30}$ Despite the common elements of many of these schemas, this fact presents considerable challenges to the University of Manitoba and its partners in achieving the goals articulated in their NRC proposal. Readying this sizable collection for public consumption, given the present metadata structures, will require an extensive amount of work. For instance, the proposal called for a broad audience being able to easily search and utilize the NRCTR's records online. In order for the NRCTR to improve the discoverability of and accessibility to its records, a common metadata schema, perhaps the one employed to describe the church and LAC archival records, may need to be selected and the existing metadata schemas may need to be normalized to this standard through field-to-field metadata mapping and Extensible Markup Language (XML) crosswalks and managed in a single database. By providing evidence of this normalization process, perhaps as the RRN did with dual tabs, users would be assured of the records' authenticity and would serve to instill trust. Normalization would enable the NRCTR, like the RRN, to build on the current limited advanced search capabilities of the system and implement a more robust, comprehensive advanced search for complex research queries where every element is searchable across the entirety of the holdings. However, as the designers of the RRN have noted, it is equally important to make the search functionality of the system as intuitive as possible to the uninitiated user. ${ }^{31}$ In an RRN usability study, the feedback provided indicated the desire for a central Google-like keyword search box, which would produce a result set that could then be further refined through easy to understand facets, ${ }^{32}$ namely "Who," "What," "When," and "Where." 33 The TRC Database already features the former but the NRCTR may wish to follow the RRN's example and implement an easily comprehensible faceted search. This approach would lend itself to realizing the NRCTR's goal of broad accessibility.

An additional metadata normalization challenge that must be faced by the NRCTR is the implementation of name authorities throughout the entire system. The TRC has developed a standardized name authority for document collection that was also circulated along with data input instructions to the church entities responsible for contributing their own records to the TRC. Unfortunately, given the multiple sources of information, many of the name authorities are still inconsistent and will need to be edited and further normalized by NRCTR staff. The name authority standard has yet to be applied to the metadata in the NRA or Active and Semi-Active Government Records Databases. Also, as noted above, the Red, Black, and School Series records are not described at an item level and do not make references to names 
mentioned in the records. While duplicates of some of these records will be described within the NRA Database given their usefulness in litigation, more research would need to be done into this record set, as well as the recorded statements within the Audio/Video Statement Database, to extract names from these records in order to create a comprehensive name authority list.

For all that a name authority might offer, however, the clear and explicit obligation of the Centre to protect personal identifying information is central. Consequently, the NRCTR must use an abundance of caution in making records containing personal information available to the public. The redaction of records and metadata is but one labor-intensive metadata normalization process that the NRCTR must face in the future.

The current TRC Database does not permit the user to browse records. If the NRCTR is to be as inclusive as possible, it may want to incorporate browse functionality as many users prefer browsing to searching as a means of access to digital records. Further normalizing the metadata of the TRC would allow the NRCTR to implement browsing. The NRCTR may wish to follow the leads of the Plateau Peoples' Web Portal and Ara Irititja projects in empowering Indigenous people to select categories, or arrangements of records, that make browsing as simple, efficient, and meaningful as possible for Indigenous users. The Plateau Peoples' Web Portal allows tribal administrators to select categories of importance to Indigenous people in addition to the institutionally provided Library of Congress Subject Headings (LCSH) in the classification of the records in the system. ${ }^{34}$ Indigenous users can then browse the records by topics of relevance to them as well as by tribal affiliation. ${ }^{35}$ The interface for the Ara Irititja Project, a community-based, multimedia digital archive designed at the request of the Anangi-speaking communities in Central Australia, classify the records in its holdings by media format (photos, documents, movies, sounds, and objects). ${ }^{36}$ Users can browse the knowledge management system created for the project by format, date, gallery albums, or by subjects of relevance to the Anangi-speaking people (called profiles), including people, events, mythology, flora, and fauna. ${ }^{37}$ In both of these examples, Indigenous people were given the authority to select classifications for the records that would aid them in discovering relevant content. The NRCTR may wish to follow suit by consulting its various user communities in selecting classifications for the records that are of value to them (e.g., location, school, Indigenous community, originating archival fonds, format) that could co-exist with more traditional forms of classification such as LCSH. Christen Withey astutely asserted that this multilayered approach to metadata challenges the expert authority but does not displace it. $^{38}$

The NRCTR will also have to determine what languages to use in the presentation of the records' metadata. Currently, the only language used in the TRC Database descriptions is English, despite the fact that French appears 
655 in some of the records. The NRCTR may want to follow the lead of the Ara 656 Irititja Project, which uses Indigenous language, as well as English, in its 657 interface whenever possible. ${ }^{39}$ By doing so, the NRCTR would demonstrate 658 its willingness to be as inclusive as possible in its attempts to reach all those 659 affected by Indian Residential Schools.

The archives of the National Research Centre for Truth and Reconciliation will be a rich source of Indigenous knowledge pertaining to one of the 663 darkest objectives of Canadian policy. Through the creation of a dynamic 664 "living archive," the NRCTR will assist the nation in overcoming the traumatic loss of language, traditional childrearing practices, sense of identity, and traditional communal value inflicted by the Indian Residential School legacy.

667 Beyond this, the archive presents Survivors who were raised away and apart 668 from their families to reconnect with some of the records of their past. 669 For instance, the NRCTR has heard numerous stories from Survivors of a 670 church archive containing the only known photograph of that person in his 671 or her youth. Getting these records back into the hands of Survivors and 672 First Nations, Inuit, and Métis communities will be a powerful act of record 673 repatriation.

674 Although the NRCTR will face challenges in utilizing the metadata set accumulated by the Truth and Reconciliation Commission of Canada in its statement gathering and document collection practices, implementing a di677 verse approach to description can assist the NRCTR in realizing its vision of 678 a broadly accessible, participatory archive that tells many stories from many perspectives. By working cooperatively and respectfully with Indigenous people through the implementation of Indigenous knowledge best practices and the application of contrasting traditional/non-traditional, archival/usergenerated, and institutional/Indigenous descriptive elements, the NRCTR can facilitate Indigenous participation, collaboration, and ultimately, the process 684 of reconciliation. 
2. Indian Residential Schools Settlement Agreement-Schedule "N"-Mandate for the Truth and Reconciliation Commission (May 8, 2006), 10, http://www.residentialschoolsettlement.ca/SCHEDULE_N.pdf (accessed August 30, 2014).

3. "The term Sixties Scoop was coined by Patrick Johnson, author of the 1983 report Native Children and the Child Welfare System. It refers to the mass removal of Aboriginal children from their families into the child welfare system, in most cases without the consent of their families or bands." Erin Hanson, "The Sixties Scoop \& Aboriginal Child Welfare," indigenousfoundations.arts.ubc.ca, http://indigenousfoundations.arts.ubc.ca/home/government-policy/sixties-scoop.html (accessed August 30, 2014).

4. IRSSA, Schedule N, 2.

5. Ibid., 2 .

6. See ibid., 10-11, for additional sections on document collection.

7. Bronson Consulting, Minisis Inc., THG: The History Group, and Breching, TRC Database Elements: Definitions and Descriptions, 2013. The TRC Database is available to authenticated users only.

8. This issue came to the fore in the St Anne's Residential School litigation to which the TRC was an intervener, where an omission of known cases of abuse was noted in the version of the school narrative supplied to the TRC. The Government of Canada claimed this was an oversight in the process and was ordered to produce a more accurate version of the document, along with the records of the police investigations of that school, to the TRC.

9. The information contained in the statement gatherer's field notes was used to populate the data in the Audio/Video Statement Database.

10. The Red and Black Series were named after the color of the letter books used by the Department of Indian Affairs to distinguish between eastern and western Canadian correspondence. Sean Darcy, "The Red and Black Series," http://www.collectionscanada.gc.ca/aboriginal-heritage/020016-2004-e.html (accessed August 21, 2014).

11. Library and Archives Canada, "Residential School Records Resources," http://www.baclac.gc.ca/eng/discover/aboriginal-heritage/resources-researchers/Pages/residential-schools-resourcesheets.aspx (accessed August 21, 2014).

12. The result sets for each database comprising the TRC Database differ in the metadata elements presented to the user. The user is able to sort the result sets by the elements that each database makes available.

13. The document TRC Database Elements: Definitions and Descriptions does not specifically define Issues but one can determine that Issues are analogous to subject terms of importance to TRC researchers in the completion of their reports. Individuals were asked to review records as they were submitted to the TRC Archives and identify and record issues in the records' metadata. A few of the issues that the TRC were most interested in being made evident in order to simplify the research process were "Abuse," "Cemetery-Site/Location," "Death Child" (as well as the cause and date of the death), "Missing Child,", and "Nutrition." For a complete list of Issue Codes, see TRC Database Elements: Definitions and Descriptions, 26-27.

14. Marie Battiste, Indigenous Knowledge and Pedagogy in First Nations Education: A Literature Review with Recommendations, prepared for the National Working Group on Education and the Minister of Indian Affairs, Indian and Northern Affairs Canada (INAC), Ottawa: Apamuwek Institute (2002), 4.

15. James (Sákéj) Youngblood Henderson, "Ayukpachi: Empowering Aboriginal Thought, " in Reclaiming Indigenous Voice and Vision, ed. Marie Battiste (Vancouver: UBC Press, 2000), 267.

16. Camille Callison, "Canada's New Canoe," in Aboriginal and Visible Minority Librarians: Oral Histories from Canada, ed. Deborah Lee and Mahalakshmi Kumaran (Maryland: Roman and Littlefield, 2014), 144.

17. University of Manitoba, Proposal-National Research Centre on Indian Residential Schools, February 16, 2012, 2.

18. Jenna Walsh, "Collaboration with Indigenous Peoples When Arranging and Describing Indigenous Archival Material," unpublished paper written for ARST 515 class, Dr. H. MacNeil, University of British Columbia, November 21, 2007.

19. University of Manitoba, Proposal, 3.

20. Ibid., 26.

21. Ibid., 40 .

22. Reciprocal Research Network, "About," http://www.rrncommunity.org/pages/about\#about_rrn (accessed August 25, 2014). 
23. Kate Hennessy, Ryan Wallace, Nicholas Jakobsen, and Charles Arnold, "Virtual Repatriation and the Application Programming Interface: From the Smithsonian Institution's MacFarlane Collection to "Inuvialuit Living History," Museums and the Web 2012, http://www.museumsandtheweb.com/mw2012/papers/virtual_repatriation_and_the_application_progr.html (accessed August 25, 2014).

24. Mukurtu, "Mission," http://www.mukurtu.org/\#mission (accessed August 26, 2014).

25. "The Plateau Peoples' Web Portal is a collaboration between the Plateau Center for American Indian Studies at Washington State University and tribal consultants from the Spokane, Colville, Umatilla, Coeur d'Alene, Warm Springs, and Yakama nations. The Plateau Peoples' Web Portal is a gateway to Plateau peoples' cultural materials held in Washington State University's Libraries, Manuscripts, Archives and Special Collections (MASC), the Museum of Anthropology and national donors including the National Anthropological Archives and the National Museum of the American Indian at the Smithsonian Institution." Plateau Peoples' Web Portal, "Project Overview," http://plateauportal.wsulibs.wsu.edu/html/ppp/help.php?topic=1 (accessed August 26, 2014).

26. Kimberly Christen, "Opening Archives: Respectful Repatriation," American Archivist 74 (Spring/Summer 2011), 199.

27. Kimberly Christen, "Archival Challenges and Digital Solutions in Aboriginal Australia," SAA Archaeological Record 8, no. 2 (2008), 23

28. Data security and access protocols are of paramount importance to the NRCTR in the design of its digital asset management system owing to the extremely sensitive and private nature of the TRC records. Content restrictions embedded into the digital objects' metadata combined with user profiles featuring varying levels of permissions and a required authentication process will ensure that users will only be able to view, create, edit, delete, or use the content for which they have been cleared to access.

29. Callison, "Canada's New Canoe," 141.

30. The TRC was limited in how it could control the document collection process. The metadata that was collected or supplied by the originating archive was generated for multiple uses, ranging from the rapid submission of records to the TRC for research (i.e., Active and Semi-Active Government Records Database), to the frequent use of the records for litigation purposes (i.e., NRA Database), to the legislated submission of large volumes of records from archives, often lacking item-level metadata. The multiple purposes for which the records were accumulated are itself a record of the overall Settlement Agreement process.

31. Lee Iverson, Susan Rowley, Leona Sparrow, Dave Schaepe, Andrea Sanborn, Ryan Wallace, Nicolas Jakobsen, and Ulrike Radermacher, "The Reciprocal Research Network," Museums and the Web 2008, http://www.museumsandtheweb.com/mw2008/papers/iverson/iverson.html (accessed August 26, 2014).

32. Susan Rowley, Dave Schaepe, Leona Sparrow, Andrea Sanborn, Ulrike Radermacher, Ryan Wallace, Nicholas Jakobsen, Hannah Turner, Sivia Sadofsky, and Tristan Goffman, "Building an On-Line Research Community: The Reciprocal Research Network," Museums and the Web 2010, http://www.archimuse.com/mw2010/papers/rowley/rowley.html (accessed August 26, 2014).

33. Iverson et al., "Reciprocal Research Network."

34. Christen, "Opening Archives," 200.

35. Plateau Peoples' Web Portal, "Browse," http://plateauportal.wsulibs.wsu.edu/html/ppp/browse.php (accessed August 26, 2014).

36. Ara Irititja Project, "The Ara Irititja Approach," http://www.irititja.com/the_archive/index.html (accessed August 26, 2014).

37. Ara Irititja Project, Ara Irititja Project—Software Brochure, 2, http://www.irititja.com/resources/ Ara\%20Irititja\%20Brochure\%20Sept\%202011-print.pdf (accessed August 26, 2014).

38. Christen, "Opening Archives," 198.

39. Ara Irititja Project, "The Software History," http://www.irititja.com/the_archive/the_software. 